ENTREPRENEURSHIP AND SUSTAINABILITY ISSUES

ISSN 2345-0282 (online) http://jssidoi.org/jesi/ 2019 Volume 7 Number 1 (September)

http://doi.org/10.9770/jesi.2019.7.1(14)

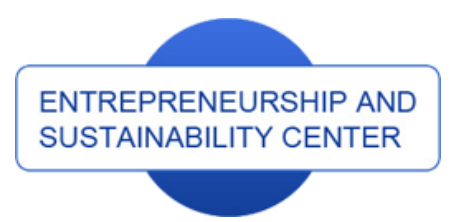

Publisher

http://jssidoi.org/esc/home

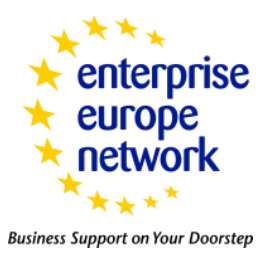

CASPA

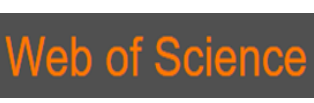

1) Clarivate

\title{
MARKETING ANALYSIS OF THE MEDICAL REPRESENTATIVES' ACTIVITY AIMED ON INFORMATION SUPPORT FOR PROMOTED MEDICATIONS*
}

\author{
E. A. Winter ${ }^{1}$, T. M. Litvinova ${ }^{2}$, D. V. Babaskin ${ }^{3}$, L. I. Babaskina ${ }^{4}$, O. V. Savinova ${ }^{5}$ \\ 1,2,3,4,5 Sechenov First Moscow State Medical University, 8-2, Trubetskaya St., Moscow, 119991 Russian Federation
}

E-mails: ${ }^{1}$ elizavetawinter@gmail.com; ${ }^{2}$ litvinova@sechenov.ru; ${ }^{3}$ babaskind@yandex.ru; ${ }^{4}$ 727838@bk.ru; ${ }^{5}$ 591686@mail.ru

Received 15 February 2019; accepted 25 June 2019; published 30 September 2019

\begin{abstract}
The purpose of the study was to analyze the medical representatives' activities aimed on information support for promoted medications. The assessment of the medical representatives' activity by doctors, pharmacists, and chemists was used to do so. The following methods of the study were used: comparative, structural and system analysis, as well as sociological methods of research (survey and interview). As a result of the study, it has been found that the activity of medical representatives is one of the main ways to obtain information about medications by medical or pharmaceutical workers, but the objectivity and completeness of the information received largely depends on the contact frequency and trust in the information materials provided. Following the results of the study, recommendations have been developed for improving the activities of medical representatives and their interaction with pharmaceutical organizations and doctors.
\end{abstract}

Keywords: medical representative; pharmacist; doctor; pharmacy; contact frequency; information; objectivity

Reference to this paper should be made as follows: Winter, E.A.; Litvinova, T. M.; Babaskin, D. V.; Babaskina, L. I.; Savinova, O. V. 2019. Marketing analysis of the medical representatives' activity aimed on information support for promoted medications, Entrepreneurship and Sustainability Issues 7(1): 177-187. http://doi.org/10.9770/jesi.2019.7.1(14)

JEL Classifications: I11

\section{Introduction}

A wide range of medications presented on the Russian pharmaceutical market today necessitates objective information about them for pharmaceutical specialists. Medical representatives of pharmaceutical companies play an important role in information support for medications.

\footnotetext{
* The study was supported by the "Russian Academic Excellence Project 5-100".
} 


\section{ENTREPRENEURSHIP AND SUSTAINABILITY ISSUES}

ISSN 2345-0282 (online) http://jssidoi.org/jesi/

2019 Volume 7 Number 1 (September)

http://doi.org/10.9770/jesi.2019.7.1(14)

A medical representative is either a full-time employee of a pharmaceutical company or an employee voluntarily engaged in the company's activities, who visits medical and pharmaceutical organizations to directly promote medications (Cubic \& Shaffer 2017; Androniceanu, 2017).

The medical representatives' activities should be considered in the context of the sociology of medicine (Salmasi et al. 2016), organization of pharmaceutical business (Lueckmann et al. 2009; Horodnic et al., 2018), pharmaceutical business and pharmaceutical market (Shang \& Shi 1999; Sierles et al. 2009), psychology (Assari 2017), and professional training for pharmaceutical specialists (Sobowale et al. 2018).

It is important to note that pharmaceutical companies are always initiators and sponsors of the medicine development, influencing the development of medicine and pharmaceuticals worldwide, contributing to the expansion of medical knowledge in the scientific community, and improving the efficiency of diagnostics and treatment, which improves the healthcare quality. In this case, medical representatives are the main communicators from companies.

It can be assumed that the profession of a medical representative developed in line with the profession of a doctor while stimulating this process. This is because pharmaceutical companies conduct intensive research into various diseases and medicine development, while medical representatives communicate information about them to practitioners (ILO maritime labour Conventions and Recommendations 2008).

The above aspects determine the relevance of the research of medical representatives' activities from the standpoint of providing information about medicines to direct partners and customers: pharmacists and chemists.

The activities of medical representatives in Russia have become especially important now due to the Presidential Decree "On the national goals and strategic objectives of the Russian Federation development through to 2024" and the implementation of the sustainable development strategy "Russia 2024" (Eskindarov et al. 2017). Priorities in healthcare were identified in the strategy for sustainable development of Russia - in particular, increasing the personal responsibility of citizens for their health, ensuring the free choice of healthcare providers of appropriate quality, providing targeted assistance to the most socially vulnerable groups of the population, and creating a business-friendly environment in the healthcare market. It must be noted that the European Union's Health 2020: a European Policy Framework Supporting Action Across Government and Society for Health and Well-Being became a guideline (Health 2020). One of the directions in addressing the healthcare priorities is to increase the role of medical representatives in the medicine promotion, securing the quality, impartiality and reliability of pharmaceutical information sources.

The purpose of this article is to analyze the activities of medical representatives to provide information support to promoted medications - from the standpoint of assessment by their counterparties (doctors, pharmacists, and chemists).

\section{Materials and Methods}

The survey method was used as the main method of researching the activities of medical representatives in order to provide information support to promoted medications, where 266 the respondents from 21 constituent entities of the Russian Federation participated. The research review included doctors, pharmacists, and chemists from 174 economic agents of various forms of incorporation.

The deterministic quota method was used for sampling. The following parameters were monitored in the study: employment history, position, and age. The field phase of the study was conducted in $2017-2018$ through a 
personal oral survey using a structured questionnaire. The questionnaire included questions relating to personal characteristics of the respondents, assessment of their needs for obtaining information about medicines from medical representatives, as well as an analysis of the level of satisfaction with the medical representatives' activities.

\section{Results}

When assessing the frequency of the medical representatives' visits to pharmacies, it was found that their level was 1-5 times a week in most cases (cumulative share of the respondents was $70 \%$ ). Only $19.2 \%$ of the respondents noted the level of the medical representatives' visits to their institutions as 6-10 times a week. The smaller number of the respondents (10.8\%) indicated more frequent visits (Figure 1).

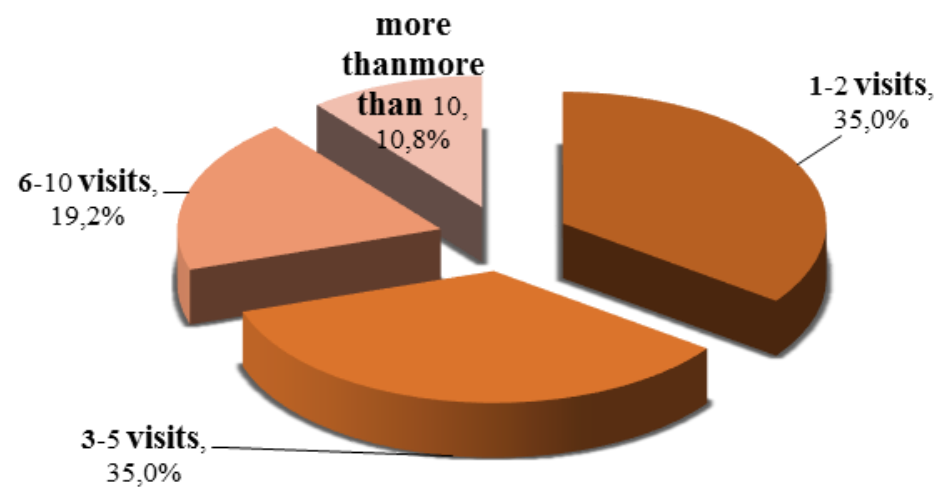

Fig.1. Frequency of medical representatives' visits to pharmacies (per week)

The authors believe that the provided data are more dependent on the geographical location of the pharmacy and its level of importance for the pharmaceutical company. It is known that there is a certain rating of pharmacies for the business potential among medical representatives:

- Category 1: large pharmacies (and chains) with high turnover, which promptly pay their invoices;

- Category 2: medium-sized pharmacies with high potential for sales growth, paying invoices in a timely manner or with a slight delay; and

- Category 3: small pharmacies or state-owned pharmacies that serve mainly low-income consumers and allowing frequent delays in payment of invoices.

Undoubtedly, the frequency of the medical representatives' visits to pharmacies largely depends on the pharmacy rating: Categories 1 and 2 attract the attention of medical representatives much more often than pharmacies from Category 3. The medical representatives most frequently visit the most successful and solvent pharmacies (6 or more times per week make up a cumulative share of 30\%). There are "supporting" contacts (1-2 times a week) with a medical representative in one case out of three (35\% of the respondents). As such, it can be argued that there is a direct connection between the number of medical representative's contacts and the rating/category of the pharmacy.

The degree of trust in medical representatives and the information they provide is an important factor in their performance. Studies reveal that employees of pharmaceutical organizations often have a negative attitude to medical representatives due to the insufficient quality of the information provided. At the same time, medical representatives often do not disclose full information about side effects of medications, omit (or intentionally 
reduce) information about contraindications of medications or allow incomplete presentation of other information about medications, mainly emphasizing its advantages without mentioning the possible risk of use (Walker \& Druss 2015).

As such, the next stage of the study was to assess the degree of confidence in the information provided by medical representatives among pharmacists and chemists (Figure 2). The results revealed that only $6.7 \%$ of the respondents fully trusted the information materials provided by medical representatives. Seven two point four percent of the respondents could trust information only after its verification. Another $20.9 \%$ of the respondents noted that they did not always and fully trust the information provided by medical representatives about a particular product.

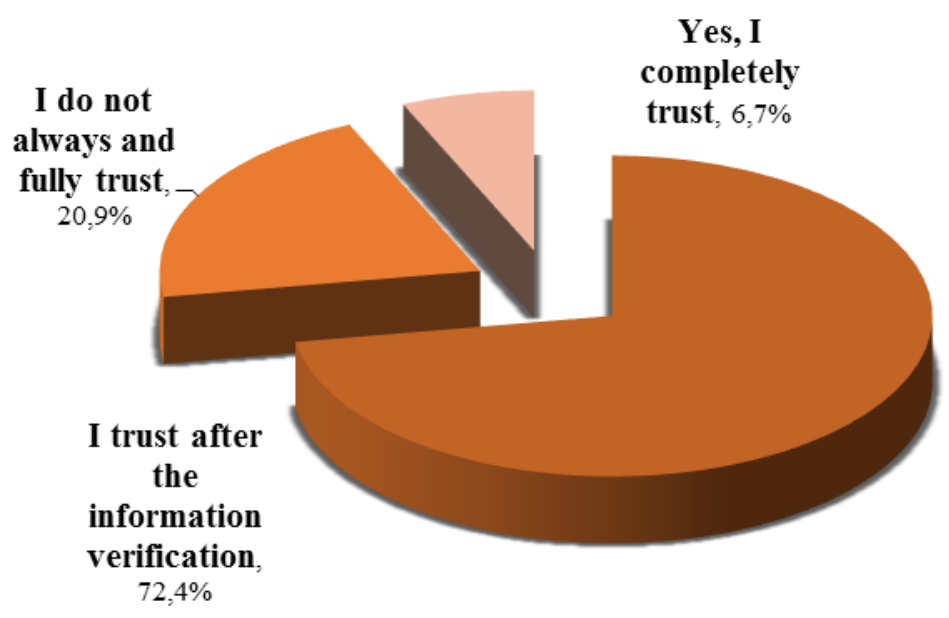

Fig.2. Assessment of the degree of trust in the information received from medical representatives by the respondents

It was established in the course of the study and interviews that pharmaceutical companies used both individual and collective forms of interaction between their medical representatives and representatives of pharmaceutical organizations and doctors in their activities. Individual meetings were used in almost half of the cases, while the remaining contacts provided for a collective approach and were hold as various seminars, round tables, and presentations.

The survey found that a certain form of interaction between medical representatives and pharmacists/chemists/doctors did not have significant impact on the recall rate for specific medication and their manufacturers. For example, regardless of the communication format, less than $40 \%$ of the respondents were able to recall which medical representatives visited them during the analyzed period. Meanwhile, the majority of the respondents recalled visits of medical representatives only from the interviewer's prompts. Given this fact, it can be assumed that the knowledge of pharmacists/chemists/doctors about medications promoted to the market by pharmaceutical companies is at the level of about $60 \%$.

This was also confirmed by the results of the respondents' answers to the question: "Name the company whose medical representatives represented broad-spectrum antibiotics" (Figure 3). 


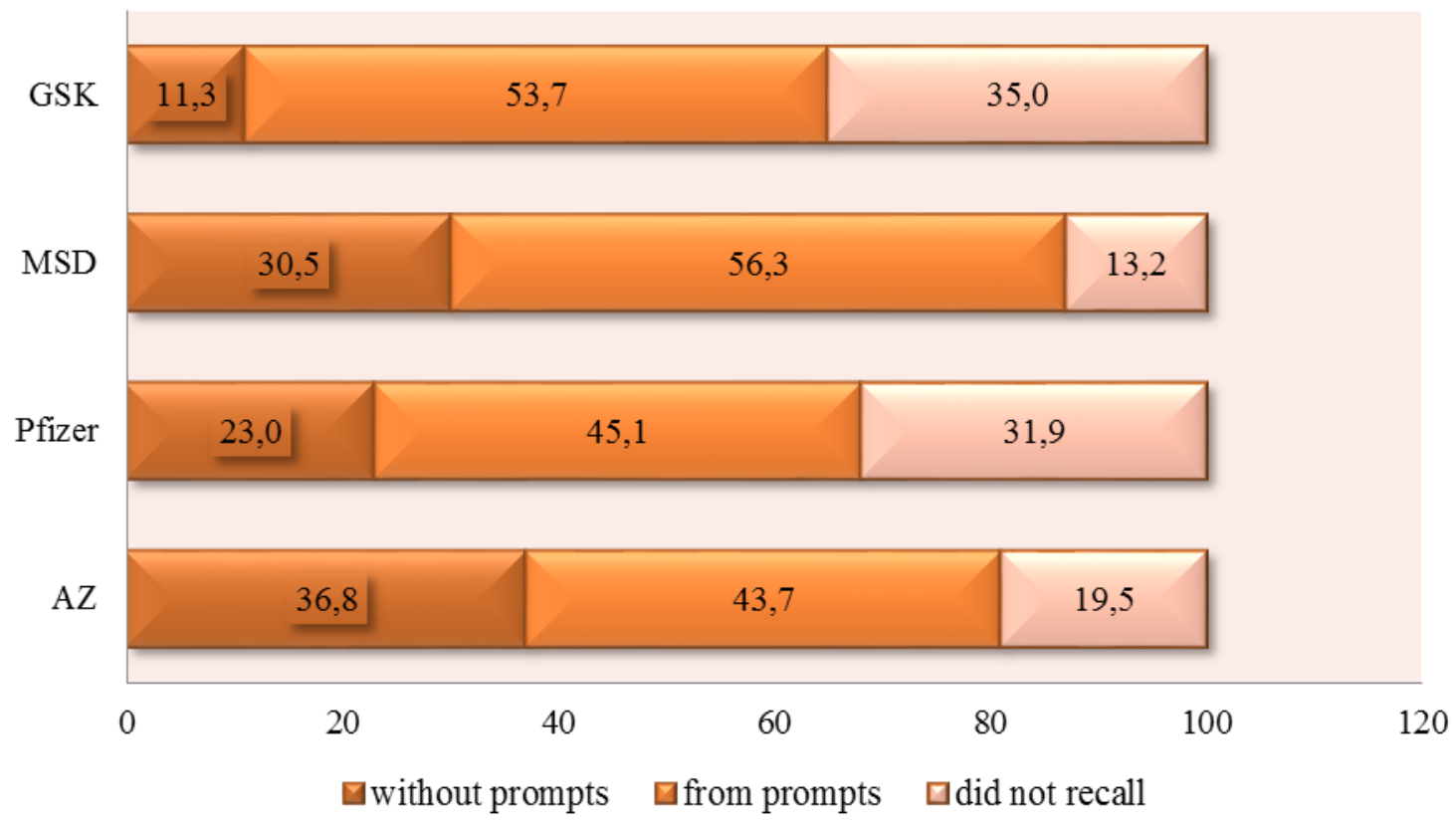

Fig.3. Recall rate by pharmacists and chemists of information on broad-spectrum antibiotics provided by medical representatives (\%)

The information presented in the figure allows to conclude that the respondents best recalled visits of Merck Sharp \& Dohme (MSD) employees, as mentioned by about $87 \%$ of pharmaceutical employees (30.5\% of the respondents answered without prompts, and 56.3\% - from interviewer's prompts). Only $13.2 \%$ of the respondents could not recall the visits of MSD representatives, which was the best result among the largest pharmaceutical companies mentioned in the survey. This indicates the prominence of MSD among pharmacists and indirectly reflects the significant number and frequent visits of MSD medical representatives to pharmacies.

More than $80 \%$ of the respondents recalled the meetings with medical representatives from AstraZeneca (AZ) devoted to broad-spectrum antibiotics $(36.8 \%$ of the respondents answered without prompts, which was the best result among the largest pharmaceutical companies mentioned in the survey; and $43.7 \%$ answered from interviewer's prompts). At the same time, almost every fifth respondent could not recall information about broadspectrum antibiotics, which had been explained by AZ representatives during the meeting.

Lower results of recall rate of information explained by medical representatives were noted by the respondents in the case of Pfizer - only $23 \%$ of the respondents recalled it without prompts. A significant part of the respondents $(45.1 \%)$ did this with the help of an interviewer, and almost a third of the respondents $(31.9 \%)$ could not recall the information explained by medical representatives of Pfizer, which indicated low efficiency of contact.

The worst results among the large pharmaceutical companies on the market for broad-spectrum antibiotics were obtained for representatives of GlaxoSmithKline (GSK) - 35\% of the respondents could not recall the information or the representative's visit, and only $11.3 \%$ of the respondents had steady memorization (the lowest result among the companies mentioned in the survey). More than half of the respondents (53.7\%) recalled the visit of a medical representative or a presentation and explained information about broad-spectrum antibiotics with the help of an interviewer. This is due to the fame of GSK in the Russian market and among pharmacists.

Higher results in the recall rate for visits and conversations were demonstrated by medical representatives of Eli Lilly and Janssen-Cilag, who promoted medications for the treatment of mental illness. Ninety three percent of 
the respondents recalled them during the survey of psychiatrists of medical institutions in 8 cities of Russia. A little worse result of the visit recall rate and information of medical representatives was obtained for Astrazenica $83 \%$ of the respondents (Figure 4 ).

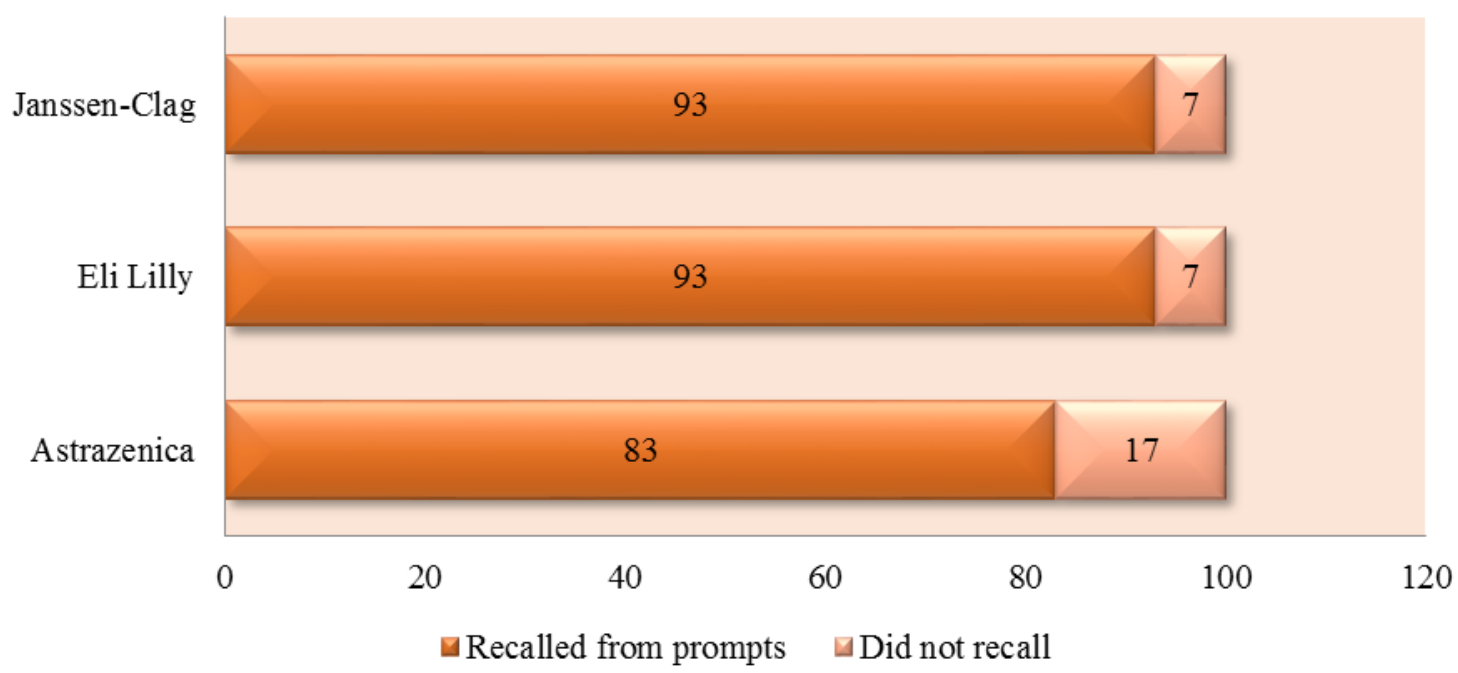

Fig.4. Recall rate for medical representatives of companies promoting medications for the treatment of mental illness by doctors

The recall rate for visits by medical representatives of the companies promoting medications for the treatment of mental illness can be better than for those promoting broad-spectrum antibiotics due to the following:

1) personal contacts with doctors (who directly use medications in their medical practice and rehabilitation) rather than with pharmacists (who act only as intermediaries between pharmaceutical companies and medical institutions/patients in this case);

2) special conditions for the use of medical items for the treatment of mental illness that are restricted and not used by a wide range of consumers; and

3) a limited number of manufacturers and pharmaceutical companies specializing in the production and promotion of medical items for the treatment of mental illness, compared with broad-spectrum antibiotics.

It must be recognized that the recall rate for visits and presentation of medical representatives, as well as information about medications promoted by them, are undoubtedly influenced by the frequency and regularity of communications, due to which the interval between regular visits of medical representatives of a particular pharmaceutical company does not usually exceed one month. However, even with such an interaction schedule, the respondents recalled on average only $40-60 \%$ of the meetings with medical representatives during a calendar month. Moreover, it was found during the survey that a significant number of the respondents (about 25\%) noted no visits from representatives of some pharmaceutical companies over 6 months.

The results of establishing the visits' frequency of medical representatives promoting medications for the treatment of cardiovascular diseases are of particular interest (Figure 5).

According to the respondents participating in a study on the promotion of medications for the treatment of cardiovascular diseases, representatives of Pharmacia were the most active in the preceding month - about $61 \%$ of the respondents recalled their visits and presentations, while $11 \%$ recalled them with the help of an interviewer. 
However, even in this situation, more than a quarter of the respondents indicated no contact with a medical representative for more than 6 months.

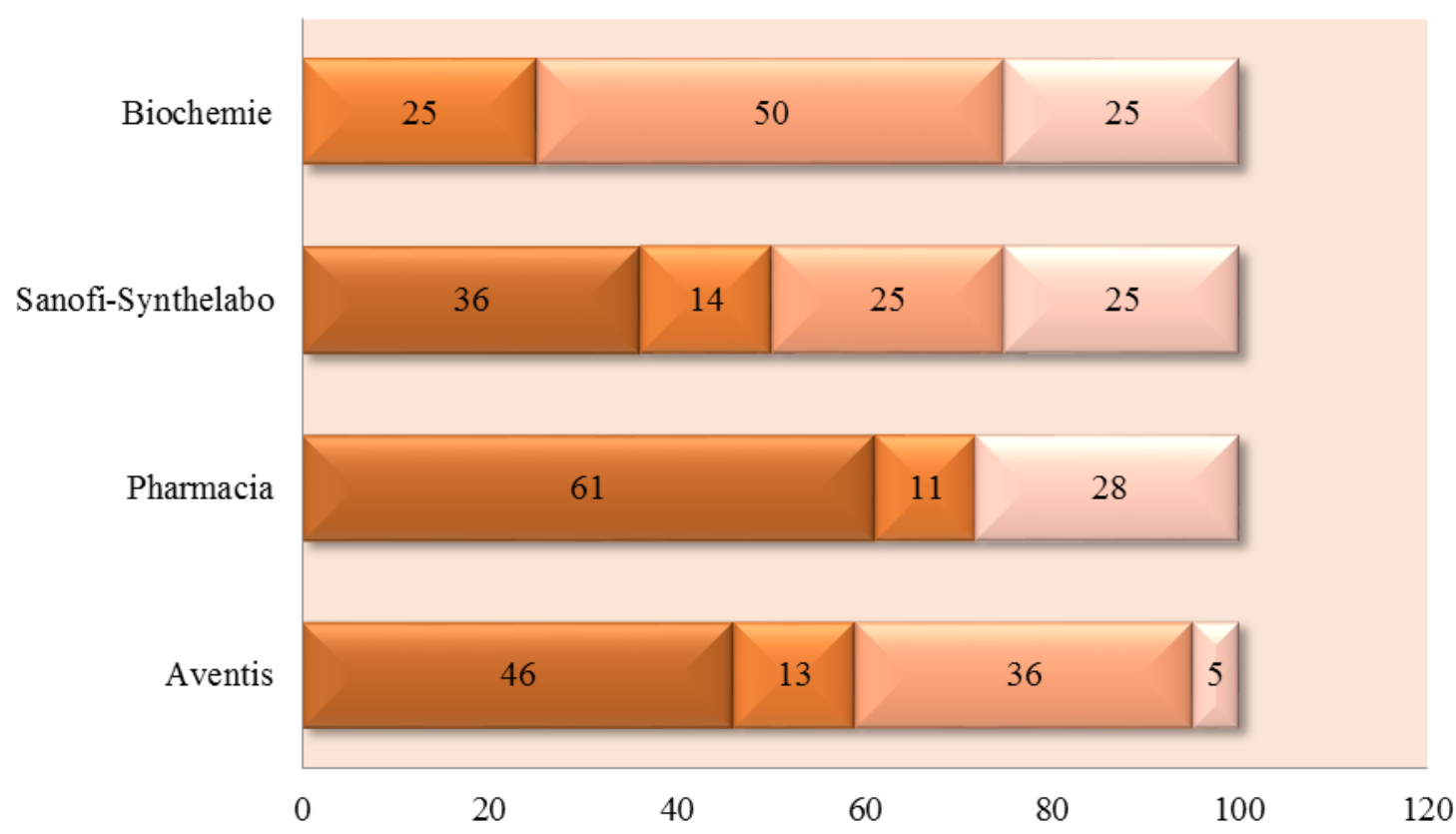

$\square$ over the past month $\square 5$ weeks to 2 months ago $\square 2-6$ months $\square$ more than 6 months ago

Fig.5. Visits' frequency for medical representatives promoting medications for the treatment of cardiovascular diseases

According to the survey results, the Aventis medical representatives were the most active: almost half (46\%) of the visits were made over the past month, another $49 \%$ of the visits were from 5 weeks to 2 months ago. Only 5\% of the respondents noted that Aventis medical representatives had visited them more than 6 months ago (this was the best result among the companies mentioned in the survey).

According to the respondents, a quarter of the visits and presentations were made more than 6 months ago by representatives of Biochemie and Sanofi Synthelabo. The former company had a quarter of contacts with medical representatives from 5 weeks to 2 months ago, and the main part (50\%) of them was from 2 to 6 months ago. Biochemie was the only company whose contacts were not made (according to the respondents) during the month preceding the survey.

The respondents recalled the representatives of Sanofi Synthelabo by their visits during the past month (36\%), from 5 weeks to 2 months ago (14\%), but half of the contacts was 2-6 months ago and earlier.

During the survey, it was found that medical representatives of companies promoting medications for the treatment of mental illness visited hospitals quite regularly - during the previous month, there had been at least one visit of Janssen-Cilag and Eli Lilly employees in about $90 \%$ cases, as well as $73 \%$ of the visits by AstraZeneca representatives. 


\section{ENTREPRENEURSHIP AND SUSTAINABILITY ISSUES}

ISSN 2345-0282 (online) http://jssidoi.org/jesi/

2019 Volume 7 Number 1 (September)

http://doi.org/10.9770/jesi.2019.7.1(14)

\section{Discussion}

A large number of ethical restrictions that exist both at the national and at the international level are the peculiarity of the modern pharmaceutical market. The WHO recommends regulating medications advertising by encouraging states to develop recommendations for market promotion of the medication that are in line with national health policies, and to promote rational use of the medication.

The WHO issued the Recommendations on the Ethical Promotion of Medications as an example of such recommendations. There is also the Association of International Pharmaceutical Manufacturers (AIRM), which annually publishes its "Code on Promotion of Medications". A large number of pharmaceutical companies proclaim their commitment to ethical operation, relying on the preservation of their reputation and do not offer consumers products the effectiveness of which has not been confirmed by scientific research, but, unfortunately, other examples also exist (Yamamoto \& Fushimi 2009; Panfiluk \& Szymańska 2017).

The world practice indicates that the assessment of objectivity and reliability of information associated with pharmacotherapy, prescription of medicines from the standpoint of evidence-based medicine, have always been discussed by many scientists and practitioners (Veelo et al. 2006). The objectivity of information on pharmacotherapy had been assessed by experts in evidence-based medicine, which allowed to determine criteria for evaluating a pharmaceutical company, through which experts could determine the quality, reliability, and usefulness of information provided to a medical representative, such as (Schmitz \& Kruse 2002):

- importance of the medication for clinical practice;

- availability of studies on the effectiveness of medicines in the leading professional journals;

- availability of highly reliable evidence (regular reviews, meta-analysis, double blind randomized controlling studies);

- breadth of the evidence, which allows to assess the safety, effectiveness, and cost of treatment;

- certainty of improvement in the living standards during the use of a particular medication;

- availability of application of indirect assessment criteria;

- clinical significance of the pharmacotherapy results; and

- availability of articles that contain the weightiest evidence of statements in the printed materials submitted by pharmaceutical companies.

It is important to note that contacts with medical representatives can also be negative: be intrusive or provide biased information. This is why programs are being adopted to protect pharmacists and doctors from the negative effects of communication in some countries, and behavior recommendations are being developed regarding the communication with representatives of pharmaceutical companies. The key recommendations include the following:

- active role of doctors and pharmacists in cooperation with medical representatives, which consists in compulsory questions regarding contraindications, adverse effects, and price of the medication represented;

- mandatory comparison of the materials provided by the medical representative with objective sources of information;

- mandatory provision of scientific information on the properties of medicines; and

- refusing free samples of medicines and other forms of attention from pharmaceutical companies.

It is important to note that one of the directions for reforming the pharmaceutical industry in Russia is the transition to the standards of proper practices in relation to the activities of pharmacies - the introduction of the Proper Pharmacy Practice (PPP). In accordance with the provisions of the standards, all processes and general activities of pharmacies should be documented. 


\section{ENTREPRENEURSHIP AND SUSTAINABILITY ISSUES}

ISSN 2345-0282 (online) http://jssidoi.org/jesi/ 2019 Volume 7 Number 1 (September) http://doi.org/10.9770/jesi.2019.7.1(14)

\section{Conclusions}

Following the results of the study, it has been found that the activity of medical representatives is one of the main ways to obtain information about medications and drugs by medical or pharmaceutical representatives today, but the objectivity and completeness of information received from a medical representative largely depend on the contact frequency and trust in the information materials provided by medical representatives.

A questionnaire survey allowed to define the frequency of visits of medical representatives to pharmacies: 1-5 times a week in $70 \%$ of cases. At the same time, an assessment of trust in the information materials provided to the medical representative indicates that only $6.7 \%$ of the respondents completely trust it, and $72.4 \%$ of the respondents intend to check this information.

The results of the study indicate that the cooperation between pharmacies' employees and medical representatives is largely not regular today on the part of pharmacies. There are also no regulatory legal acts at the state level to regulate the activities of medical representatives, and this complicates the work of both representatives and employees of pharmacy institutions.

The global practice of regulating information about medications and the formation of national policies require to define a responsible regulator, whose authority should include the creation of an efficient system of interaction between medical representatives and other specialists. This is why it seems expedient to create a nongovernmental organization in the Russian Federation that could unite players on the pharmaceutical market, conduct market and interaction analysis, and produce recommendations that could be adopted at the state level.

According to the PPP concept and ideology, any activity in the pharmacy should be documented. To comply with this provision, it is advisable to introduce a person responsible for cooperating with medical representatives, implementing and maintaining the register of medical representatives' visits to the pharmacy. This will allow tracking contacts with representatives of medical and pharmaceutical companies and their main results, and systematize the interaction of counterparties.

\section{References}

Androniceanu, A. (2017). Hospital management based on the relationship between doctors and patients. Administratie si Management Public (29): 41-53.

Assari, S. (2017). Number of Chronic Medical Conditions Fully Mediates the Effects of Race on Mortality; 25-Year Follow-Up of a Nationally Representative Sample of Americans. J Racial Ethn Heal Disparities 4(4): 623-631. https://doi.org/10.1007/s40615-016-0266-4

Cubic, B.A.; \& Shaffer, L.A. (2017). Academic Health Center Psychology Representation to the Council of Faculty and Academic Societies (CFAS) of the Association of American Medical Colleges (AAMC). J Clin Psychol Med Settings 24(2): 124-131. https://doi.org/10.1007/s10880-017-9500-4

Eskindarov, M.A.; Maslennikov, V.V.; Abramova, M.A.; Lavrushin, O.I.; Goncharenko, L.I.; Solyannikova, S.P.; Abdikeev, N.M.; \& Morkovkin, D.E. (2017). The CSR Strategy for 2018-2024: Slogans, Myths and Reality (Expert Opinion of Financial University). Bulletin of The Financial University 21(3): 6-24. https://doi.org/10.26794/2587-5671-2017-21-3-6-24

Health (2020). Retrieved August 18, 2018 from www.ndphs.org/documents/3239/NCD_5_6_3-Info_2_rus_Health_2020_WHOEURO_short.pdf

Horodnic, A.; Brock, G.; Cristian Incaltarau, C. (2018). Transition and Mortality Impact in Post-Communist Romania. Transformations in Business \& Economics 17(1-43), 21-37. 


\section{ENTREPRENEURSHIP AND SUSTAINABILITY ISSUES}

ISSN 2345-0282 (online) http://jssidoi.org/jesi/ 2019 Volume 7 Number 1 (September) http://doi.org/10.9770/jesi.2019.7.1(14)

ILO maritime labour Conventions and Recommendations. (2008). In: Maritime Work Law Fundamentals: Responsible Shipowners, Reliable Seafarers. Berlin, Heidelberg: Springer Berlin Heidelberg, 9: 415. https://doi.org/10.1007/978-3-540-72751-4 2

Lueckmann, S.L.; Behmann, M.; Bisson, S.; \& Schneider, N. (2009). Good idea but not feasible - the views of decision makers and stakeholders towards strategies for better palliative care in Germany: a representative survey. BMC Palliat Care 8(1): 10 https://doi.org/10.1186/1472-684X-8-10

Panfiluk, E.; Szymańska, E. (2017). The measurement of the innovativeness of health tourism services using an adequacy matrix title of the article. Entrepreneurship and Sustainability Issues 4(4): 400-420. http://doi.org/10.9770/jesi.2017.4.4(1)

Salmasi S.; Ming L.C.; \& Khan T.M. (2016). Interaction and medical inducement between pharmaceutical representatives and physicians: a meta-synthesis. J Pharm Policy Pract 9(1): 37. https://doi.org/10.1186/s40545-016-0089-z

Schmitz, N.; \& Kruse, J. (2002). The relationship between mental disorders and medical service utilization in a representative community sample. Soc Psychiatry Psychiatr Epidemiol. 37(8): 380-386. https://doi.org/10.1007/s00127-002-0567-2

Shang, Y.; \& Shi, H. (1999). A Web based multi agent system for interpreting medical images. World Wide Web 2(4): 209-218. https://doi.org/10.1023/A:1019261025204

Sierles, F.; Brodkey, A.; Cleary, L.; McCurdy, F.A.; Mintz, M.; Frank, J.; Lynn, D.J.; Chao, J.; Morgenstern, B.; Shore, W.; Woodard, J. (2009). Relationships Between Drug Company Representatives and Medical Students: Medical School Policies and Attitudes of Student Affairs Deans and Third-Year Medical Students. Acad Psychiatry 33(6): 478-483. https://doi.org/10.1176/appi.ap.33.6.478

Sobowale, K.; Ham, S.A.; Curlin, F.A.; \& Yoon, J.D. (2018). Personality Traits Are Associated with Academic Achievement in Medical School: A Nationally Representative Study. Acad Psychiatry 42(3): 338-345. https://doi.org/10.1007/s40596-017-0766-5

Veelo, D.P.; Spronk, P.E.; Kuiper, M.A.; Korevaar, J.C.; van der Voort, P.H.J.; \& Schultz, M.J. (2006). A change in the Dutch Directive on Medical Research Involving Human Subjects strongly increases the number of eligible intensive care patients: an observational study. Intensive Care Med. 32(11): 1845-1850. https://doi.org/10.1007/s00134-006-0384-2

Walker, E.R.; \& Druss, B.G. (2015). Rate and Predictors of Persistent Major Depressive Disorder in a Nationally Representative Sample. Community Ment Health J. 51(6): 701-707. https://doi.org/10.1007/s10597-014-9793-9

Yamamoto, K.; \& Fushimi, K. (2009). Travel of patients to distant hospitals for elective surgery in Japan: A cross-sectional analysis of a nationally representative sample. Surg Today 39(9): 758-763. https://doi.org/10.1007/s00595-009-3991-Z

\section{Aknowledgements}

The study was supported by the "Russian Academic Excellence Project 5-100". 


\section{E. A. WINTER}

https://orcid.org/0000-0002-8260-198X

\section{V. BABASKIN}

https://orcid.org/0000-0001-7548-8395

\section{I. BABASKINA}

https://orcid.org/0000-0002-2236-6818

\section{O. V. SAVINOVA}

https://orcid.org/0000-0001-6665-3643

T. M. LITVINOVA

https://orcid.org/0000-0003-0707-3045

Copyright (C) 2019 by author(s) and VsI Entrepreneurship and Sustainability Center

This work is licensed under the Creative Commons Attribution International License (CC BY).

http://creativecommons.org/licenses/by/4.0/

(c) (1) Open Access 